\section{Sociobiology and the Moral Status of Nonhuman Animals}

\author{
Rosemary Rodd \\ Cambridge, U.K.
}

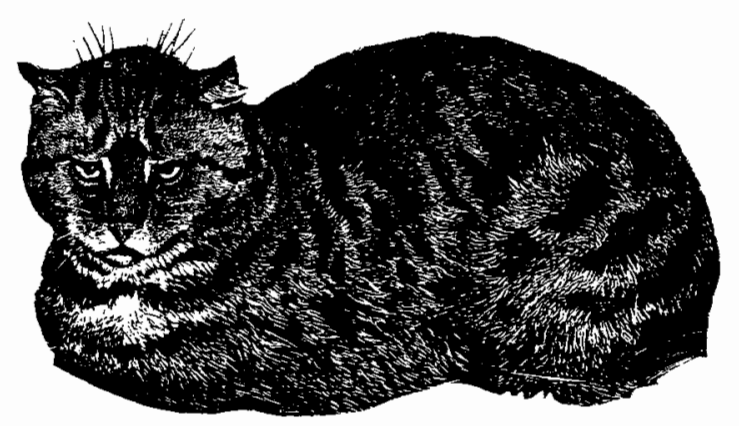

R.D. Alexander (1987) has proposed that the ultimate grounds of ethics are evolutionary. Humans have the capacity for moral reasoning and negotiation, together with a system of appropriate emotions, such as shame and guilt when we do wrong, and a sense of moral wellbeing when we do right, because these abilities tended to increase our ancestors' inclusive fitness in the past. Fairly simple mathematical models can illustrate how this could work-one example is the Prisoner's Dilemma problem in which two individuals must act cooperatively if they are to maximise their "survival points' over a series of interactions (Axelrod, 1984). In the Prisoner's Dilemma, mutual cooperation leads to an intermediate score for both parties; mutual defection gives both a low score, but if one cooperates and the other defects, then the cooperator scores no points, while the defector scores maximum points. Over a series of games the program that achieved the best scores was one called TIT FOR TAT, which cooperated unless its partner defected, but after a defection subsequently did whatever the partner did on the previous round, thus 'punishing' defection and 'rewarding' cooperation.

It might appear that an evolutionary theory of the origin of ethics can never be compatible with the

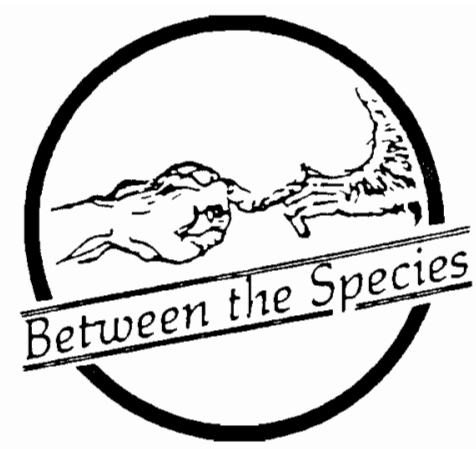

inclusion of nonhumans in our moral systems, because any tendency to give weight to their interests would always be disadvantageous; would tend to reduce inclusive fitness, and hence would involve a basic conflict with the ultimate grounds of human ethics. I hope to show that this strong view of the impossibility of animal rights is untrue, although there are grounds for holding a weaker view that proposes that, when interests conflict, humans will always have some tendency to favour relatives over non-relatives, friends over strangers, and other humans over nonhumans.

Alexander himself believes (pp. 156ff.) that the selective value of indirect reciprocity may be enough to account for a human tendency to give sentient animals some status in their moral systems. He suggests that a person who (for example) was observed by other humans to be kind and reliable when handling pet animals would appear to them to be more trustworthy than someone who behaved cruelly. Trustworthy people would tend to be given preferential treatment, and, if it is true that behaviour towards animals tends to be a good predictor of future behaviour towards other humans, then there would be selection both for kindness towards animals and for a tendency to approve of such kindness in other people. The approvers benefit by being able to make successful predictions about the behaviour of other people because they are enabled to 'invest' help in partners who are likely to reciprocate.

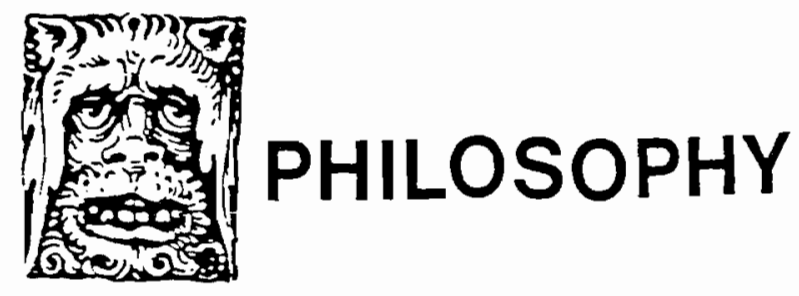


Alexander seems slightly dubious whether we should regard these feelings as real moral sentiments if they are based on the 'selfish' behaviour of the genes. However there does not seem to be any good reason why we should not say that people have real emotions of friendliness towards (some) animals and real feelings of approval and disapproval when they are treated well or badly. $f$ these feelings are ultimately caused by the selection of genes to produce nervous systems that respond in particular ways to certain environmental conditions this does not affect their reality. We do not, after all, believe that our sensations are illusory just because there are good evolutionary reasons why they should have evolved.

A real difficulty with the idea of indirect reciprocity as the sole ground for inclusion of animals in our moral system seems to me to be the suggestion that our behaviour towards them is only significant as a marker of potential behaviour towards other humans. Thus, Peter Carruthers argues in his book The Animals Issue (1992, pp. 153f.), that we have no direct duties to animals, merely a duty to our fellow humans not to behave in ways that would tend to erode our capacity for sympathy, because this capacity is beneficial to the smooth functioning of society. For Carruthers, sentient animals do not have a status in their own right but moral behaviour towards them is just a marker, or signal, of particular kinds of human behavioural disposition, or perhaps a kind of training. There seems no reason why something else should not be substituted, such as moral behaviour towards cars, bicycles, plants or rocks. However, this implies that our moral behaviour is consciously calculated in a way it probably is not. Behaviour towards animals is a significant predictor of behaviour towards other humans because it is a response to something humans and animals have in common, not because we are deliberately saying, "look what a decent person I am," when we treat animals well. If I observe that someone habitually avoids hurting animals then that is good evidence that he or she is a kindly individual who is distressed by suffering exactly the kind of person I would want to have about if I were ever in trouble. Conversely, someone who deliberately hurts animals very probably would have no compunction about hurting me and I would be very well advised to avoid them. Behaviour towards mere objects tells me very little about a person's character, at most, perhaps it may show whether she is careful or wasteful, whether she appreciates art and so on. Thus, even if we believe that the way we behave towards animals is ultimately only important because of its relevance to behaviour towards humans, sentient animals have a particular significance because they are the only entities besides humans themselves who can function in interactions which test attitudes towards mental events.

If consideration for animals were no more than a method by which humans could signal to one another that they were worthy candidates for cooperative interactions, then there would be an immediate probability of deceptive signaling. This, in turn, would lead to selection pressure for an ability to detect individuals who were merely pretending and not really experiencing a concern for animals' suffering, which would restore the significance of animals' consciousness as the basis of their moral status.

Humans' capacity to act morally must depend on a constellation of abilities, several of which seem likely to be relevant to our behaviour towards other species. One essential element of moral capability must be the ability to understand that other individuals have minds and feelings similar to one's own. Without this, none of the plausible theories of ethics could function. This ability would confer benefits independently of any involvement with our moral capability. For example, there is a considerable amount of evidence that we are able to predict the behaviour of other individuals by simulating or modeling their minds (Whiten, 1991). This ability improves with age and experience-for example, four-year-old children find it very difficult to distinguish between the information needed to allow another person to be sure what will happen in a test and that which will only allow him to guess (because two or more outcomes are equally likely). They also have trouble predicting that two-year-old and six-year-old children will act differently. Three-year-old children are aware that other individuals have feelings and wants, and they are able to use these concepts to explain their behaviour, "the boy went out because he wanted to play in the snow." However they find it difficult to understand the concept of true and false beliefs, for example a trick in which a Coca-Cola tin was filled with milk in the children's presence and then offered to an individual who had just entered the room did not seem to make any sense to them.

This may be partly due to an inability to understand their own thought processes and reasons for believing something is true. It has been shown that 3 year olds 
can successfully play a game in which they must make a choice between three inverted cups (one of which covers a sweet) if the sweet is hidden in their presence, or if an experimenter points to the correct cup, but they cannot explain how they know which cup is correct. Four-year-old children, on the other hand, have no difficulty in explaining that they know the sweet is there 'because I saw you hide it' or 'because you pointed to that cup.' These results are paralleled by tests in which the children had to choose between a cup pointed to by someone they knew had seen the sweet hidden and one pointed to by someone who was blindfolded while the sweet was hidden. Four-yearolds had no difficulty in predicting that only the person who saw the sweet hidden could point it out, but three year olds did not seem to be able to make the distinction. This seems good evidence that understanding of one's own mind is a necessary condition for understanding the minds of others.

This kind of experiment illustrates very clearly how possession of a successful 'theory of mind' enables the child to become increasingly competent in understanding and predicting the behaviour of other people and functioning within society. Children who lack the ability to develop a normal theory of mind are drastically handicapped in comparison, and this appears to be the cause of childhood autism. Autistic children have great difficulty in deciding what other people are thinking and appear to achieve such insight only as a result of laborious 'behaviourist' reasoning. Like threeyear olds, they are unable to make sense of false-belief tasks and jokes, and this does not seem to be simply a function of level of intelligence, since Downs Syndrome children with a mental age of 4 or more have no difficulty with these tests. Interestingly, autistic adults have been reported as complaining that they "could not read people's thoughts like other people" (Howlin and Rutter, 1987, p. 79), and seem to need to learn to understand social cues by a laborious process of memorisation.

Normal people seem to gain insight into the minds of others by a process of imaginative sympathy (Harris, 1991). By simulating the minds of others they are able to make successful predictions that enable them to become effective members of their society. However, this kind of simulation means that the simulator experiences a 'mirrored' version of the simulated mind. This effect must provide a powerful motivation to act according to the "golden rule" of Do-as-you-would-be- done-by. See Laurence Blum's article, 'Particularity and Responsiveness' (1987) and Iris Murdoch's The Sovereignty of Good (1970) for further arguments that there is a natural connection between knowing about distressed states and being motivated to relieve them.

The ability to think about the mental states of others is an essential basis for true morality. Individuals who lack this cannot be moral agents because they can have no conception that their behaviour can be good or bad for others, only at most a conception that some kinds of action may cause reprisals from others or may cause them to cry out. However, individuals who do possess the ability to think about mental states are not restricted to thinking about the mental states of other moral agents. If such individuals have a reason to simulate the mental states of other animals they will experience the same kind of motivation to avoid causing suffering and to promote happiness that they experience when simulating the mental states of other humans.

Angus Ross (1983) makes the interesting related suggestion that the human ability to perceive distress in others is a capacity that evolved by generalisation from a more specialised ability to perceive the distress of young that is possessed by many other vertebrates. He argues that recognition of distress is not developed by induction from understanding of one's own mental states, but that there exists a primitive condition in which the animal can recognise and respond appropriately to distress in some others and can experience distress, but lacks the cognitive ability to understand the correspondence between these two situations. In this primitive condition, action to relieve perceived distress has survival value because it will usually mean that related individuals are helped to survive. With the evolution of more general capacities for thinking about mental events, certain species developed the ability to understand the correspondence between distress in oneself and in others.

For Ross, the human capacity to think about the self as an individual in distress (rather than just experiencing distress), is a 'bottom-up' process that depends crucially upon a pre-existing ability to perceive and label distress in others. A species that did not have such a pre-existent capacity would be unlikely to evolve complex social cognition. Humans who are born without the primitive capacity to recognise distress will not develop normal social cognition. In this paper, I have generally assumed that understanding of other minds is a 'top-down' process in which self-conscious analysis of one's own 
mind and simulation of others play the predominant parts. However, it seems likely that both kinds of process are important, and, in particular, a defect in some of the primitive systems for perceiving emotions in others could explain why autistic children appear to react abnormally to other people at very young ages when even normal children are not expected to have a theory of mind. Ross's theory is also interesting because it suggests that altruism has its roots in cooperative processes where the signaling and recognition of distress benefit both interacting parties. For example, an older sibling can safely play-fight with a younger one if he breaks off the fight as soon as it gets too rough, but he can only tell if the game is too rough if he can recognise distress signals from the infant.

The severe handicap of autistic children suggests that, if it is true that (some) other species of animal have minds, then humans who can think about animals' minds by a process of imaginative sympathy will be much more successful in practical contacts with animals than those who are determined that they will be objective (Hearne, 1987, pp. 229-230). It seems that subjective thought about aninals allows us to improve our social skills of interaction with animals in ways that nothing else can.

There is some evidence that the formation of social bonds between humans and animals has practical implications-for example fear of humans has been shown to be a significant factor in farm animal production and stockworkers with good relationships with their animals improved farm productivity (Hemsworth, Barnett and Coleman, 1992). In the same voluine, Gordon Burghardt, notes:

Captive bears, because of their large size and ability to maul human beings quickly, must be adapted to people so that experimental work can be carried out safely. Thus, the separation of both experimenter and emotion from the training procedures in scientific studies with bears is just not possible. (Burghardt, 1992)

\section{And Sharon Crowell-Davis:}

Many researchers of horse behaviour whom I know personally have a major interest in the species that extends outside their professional life. Many own horses, and some would call themselves "horse-lovers." Most have at least some experience with the species. Previous experience with horses probably has a significant effect on whether researchers become involved in studies of them. Research on horses is potentially dangerous, and one inust be experienced in handling them and interpreting their behaviour sufficiently to anticipate future movements that might cause injury. (Crowell-Davis, 1992)

Oral evidence about the training of farm horsemen collected by George Ewart Evans also suggests similarities between the social mechanisms by which humans learn to cope with their own kind and those which they use to handle working animals. One informant related how, from the age of three, he learned the names of all the farm horses and their individual characters. If he was ill and unable to visit the stables, his father would describe in detail how each horse had behaved that day. (Evans, 1979, p. 99). Similarly, the psychologist and riding instructor Moyra Williams (1971) suggests that observational knowledge of animals' behaviour has to be 'compiled' into intuitive mentalistic reasoning about their thoughts and emotions if we are to be able to anticipate their future reactions quickly enough to avoid getting hurt.

The anthropologist G.P. Murdock (1980) confirms the special emotional relationship that exists between humans and their domestic animals:

...mutuality, as I am aware from having spent my boyhood and youth on a subsistence farm where I interacted intimately not only with milch cows but also with draft oxen and riding, driving and draft horses. My relations with all of them were characterized by a substantial measure of mutual confidence, respect and even affection, coupled with a sense of noblesse oblige...

Murdock believes that his statistical analysis of the prevalence of different religious beliefs in primitive societies has shown that there is a very distinct psychological difference between the practice of slavery and the use of working animals $(1980$, p. 86).

Rheinhold Bergler (1988), concludes from his comprehensive study of the psychology of the humandog relationship that this is essentially social and bidirectional, with the human partners gaining the 
psychological and physical health benefits of association with dogs only if they are prepared to enter into a mutual relationship. Potential dog owners who viewed dog-ownership in purely 'rational' terms (more exercise and so on) were unlikely actually to take the step of acquiring an anirnal (p. 126).

If a moral sense depends upon imaginative sympathy with others this could counter the objection that evolutionary explanations of morality fail because they cannot explain why we feel that wrong actions would remain wrong even if natural selection happened to 'approve' of them. Since we all have direct experience of good and bad conscious events in our own lives and since one important part of a moral sense is the ability to imagine the feelings of others, there is a natural link between the moral sense developed by evolution and the values (also ultimately developed by evolution) of certain types of conscious experience. Thus, an evolution-based moral sense will tend to have a nonarbitrary structure in a way that parallels the natural structuring of consciousness by the connection between pain and injury. It is possible to imagine a creature who had no tendency to avoid painful experiences, but such an animal would be unlikely to leave descendants. Similarly, a moral sense that approved, or was indifferent to, the infliction of suffering would imply something very wrong with its owner's capacity to simulate the feelings of others. A rational agent who lacked all sense that pain is an evil in itself would not be able to understand the motivations of other agents and, like the autistic patients, would be at a loss to predict what they might do next. This perhaps explains why Peter Carruthers (1992) cannot be content with the conclusion that we have no duties to animals because they are not contractors, but feels himself compelled to claim that they are mere automata. Because of the link between pain and damage, a moral sense that evolved because of a need for social cooperation would have to include a sense that pain is an evil for others as well as the self. Someone who did not understand this would not understand the minds of others at all, and someone who went about inflicting pain without provocation could not possibly be accepted as a cooperator.

Once a moral sense exists and includes the belief that pain is an evil, then there is no good reason to exclude individuals, such as children and animals, who are not able to demand consideration. Contrary to Peter Carruthers' claim (1992, pp. 98ff.) that the most plausible version of an evolutionary theory of morality is contractualist and that only rational agents will have any moral status in the resulting society, a natural moral sense would be expected to possess utilitarian elements. It might be possible to suggest a mixed view in which rational agents who already have some basic views about the values of other individuals' mental states make rules that depend upon a combination of self-interest and concern for others. There are no logical reasons that compel rational agents acting under a veil of ignorance to choose rules that give protection to individuals who are not fully rational. However, if the only actual rational agents who exist are ones who have been produced by evolutionary processes, then these agents may be subject to constraints which mean that they are in fact compelled to give some kind of moral consideration to all conscious individuals. The deliberate decision to exclude from protection those individuals who are conscious, but not capable of logical rationality is itself a moral consideration of those individuals. If we had really evolved to care only about what happens to rational agents there would only be a problem about animals' rights in the case of those species where we are unsure whether they should be classified as rational agents or not.

A second possible objection to a view of an evolutionary grounding for animals' rights is the claim by some biologists (e.g. Kennedy 1992) that we have no good reason to believe that animals have sensations of any kind. There seem to be two main points at issue here. Firstly, it is sometimes simply claimed that it is illegitimate to assume that animals have subjective experiences because there is no way in which this can be scientifically proved. This claim can be countered in much the same way as sceptical claims that no-one has a good reason to believe in any subjective experiences other than her own, or that no-one has reason to believe that there is any real world which exists independently of her own mental experiences. Asecond, and more interesting claim, is that sensations themselves are generated by reasoned introspection of the self and that animals who do not show this kind of ability to reason probably have no experiences. There are two objections that can be made against this. On the one hand there is evidence that some species of animals do possess self-awareness, at least to a degree that is comparable to young human children, so this view of consciousness does not exclude all species of animals from moral concern. Chimpanzees seem to perform at about the level of four-year-old children in the 'hidden 
sweet' test described earlier, since they choose to respond to pointing by an experimenter they know has seen the sweet hidden in preference to one who has not. Since, in human children, success or failure in this test seems to be correlated with ability to explain the connection between seeing and knowing, this appears to be good evidence that chimpanzees have at least this much introspective understanding of their own minds. Furthermore, if consciousness depends on some level of information processing, since we know that fouryear-old humans are conscious because some of us can remember being four years old, chimpanzees must also be conscious.

The evidence from young children also demonstrates how painfully difficult thinking about thinking actually is. Because it comes naturally to us as adult humans we have a tendency to suppose that reflecting about our thoughts is a simple process that really is rather like turning a light on our own minds. Thus Peter Carruthers claims (1992, pp. 185-6) that the observation that chimpanzees cannot use self-critical thought to avoid wasting time and energy when searching for pieces of hidden food proves they cannot think about their own thoughts at all, and are probably non-conscious. Amore plausible account of animal thought seems to be that the animal spends most of his time in a 'sea' of unexplained experiences where decision-making generally feels like guessing does to us. He may know that an object is present but cannot know how he knows. This would be a very disturbing state of affairs for an adult human, but, like our two or three year olds, the animal experiences no pressing need for an explanation of his world in terms of serial logic. At the level of the chimpanzee, or of the human four-year old, the animal is just beginning to develop the power of explanation, and to know that he thinks there is a sweet hidden because he saw it put under the jar.

Comparison between young humans and adult animals must be used with caution but this kind of study may at least suggest significant avenues for investigation of what their experiences must be like. For example, human two-year-olds seem to understand desires, but not beliefs (Wellman, 1990, pp. 207-242). Accordingly, it would be expected that animals less intelligent than the chimpanzee will fail on "theory of mind" tasks that require attribution of belief (like the hidden sweet task), but might still succeed on ones that only require an understanding of motivation. This is potentially significant if we are interested in the sorts of points which Peter Singer and Tom Regan have discussed concerning the wrongness of killing animals. Both these authors are interested in the question of whether some kinds of animals are 'subjects of a life' or 'persons' rather than simply composites of immediate sensations. Philosophers have usually tended to hold that there is a tight connection between desire and belief, and that an organism can not be said to desire something unless it also has beliefs about that something. The evidence from young children may indicate that desires are prior to beliefs (since understanding of desires precedes understanding of beliefs), and that it is possible for an organism to have experiential desires without anything like adult human beliefs.

If Kennedy (1992) is correct in his hypothesis that consciousness is actually generated by the ability to process information about the brain's own states this would imply that most animals other than apes, possibly some monkeys, and perhaps elephants and some cetaceans, do not have sensations. However, both Kennedy (1992, p. 23) and Humphrey (1986) base their arguments on the assumption that conscious experiences are the only way in which an entity could use information about itself to interpret the activity of another entity. It seems to me that this is demonstrably false, since it is perfectly possible to imagine a computing system which could run a simulation of itself; compute the effects of varying inputs and use the output to predict the activity of a different machine. (In fact so-called 'virtual machines' are already very commonly used for various purposes).As Searle has argued there is no reason to believe that such a machine would have sensations or experiences. If consciousness is not the product of self-referential informationprocessing, the lack of self-reference in any species is not evidence of lack of consciousness.

A third type of objection to a view of rights that includes some animals is that no-one can have rights unless they also have duties, or at least some kind of capacity for moral action. Ross's suggestion (1983) that the human capacity for altruism is based upon more primitive abilities to recognise distress in members of one's own species might lead us to the idea that some animals may have proto-moral capacities that we ought to value.

Vicki Hearne (1987) has suggested that the trainability of domestic animal species is a variety of proto-moral behaviour, rather similar to early moral behaviour of young children that is mainly based on 
obedience to respected adults. H. Davies (1989) has criticised the idea that trained obedience in animals bears any relation to morality in humans, stating that he has demonstrated by experiment that rats who are punished for eating food they are not 'supposed' to, do not develop a bad conscience, but simply learn to avoid eating when a human who might deliver punishment is nearby. This raises several interesting questions about the way in which true obedience (rather than simply punishment-avoidance), depends upon the relationship between the teacher and learner. It might be argued that the crucial difference between Vicki Hearne's dogs and Hank Davies' rats lies in the fact that dogs characteristically have a social relationship with humans in which the human partner acts as a legitimate source of authority, but there is no reason for the rats to obey-why should they? This does not imply that rats or dogs have a sophisticated ability to reason about sources of authority - one can imagine a rather simple system of proto-moral behaviour that could be compared to pre-schoolers obeying a known teacher, but not one they think is not 'supposed' to be in the classroom (Shweder, 1987).

...A teacher from another classroom appears at the door with a child from her unit. Alice addresses them.

1. ALICE: What are you doing in our class?

2. TEACHER: Well, we came up the stairs and we didn't know where we were going and here we are.

3. ALICE: Get out of our class.

...

6. MR PRICE [Alice's own teacher]: You should be friendly to visitors. (p. 204)

As with the idea that there are primitive capacities which underlie the human ability to generate a theory of mind, caution is needed in equating phases in human ontogeny with phases in the evolution of the human species. This is even more true if one is trying to equate them with the capabilities of adults at the ends of different evolutionary pathways. The validity of such comparisons will largely depend upon the extent to which three requirements are true.

Firstly, that there are proto-moral impulses (such as reciprocal food-sharing) which would have survival value for any evolved social species. Secondly, that an ability to predict the behaviour of conspecifics will have value for members of such species. Thirdly, that these behaviours will then be modified by the amount of nonmoral evaluative capacity which the animals are able to bring to bear.

Kathryn Paxton George (George, 1992) suggests that animals with proto-moral social behaviour should be regarded as 'virtuous agents' to the extent that they do act according to morally valuable impulses, but not as moral agents because they cannot make a moral choice to act virtuously. If this is so, these animals must have something at least very similar to duties, and the ability to remember and reciprocate good and bad treatment (tit-for-tat) which is such an important part of protomoral behaviour comes very close to the kinds of ability demanded for a Rawlsian method of decision-making.

If morality depends upon the possession of a theory of mind, and some animals have a primitive T.O.M., then these animals possibly also have genuine protomoral behaviour, and hence a special value in a theory of ethics which bases rights upon the possession of duties.

\section{References}

Alexander, R.D., (1987) The Biology of Moral Systems, (New York: Aldine de Gruyter)

Axelrod, Robert M., (1984) The Evolution of Cooperation, (New York: Basic Books)

Bergler, Reinhold, (1988) Man and dog: the psychology of a relationship, (Oxford: Blackwell Scientific Publications).

Blum, Lawrence, (1987), "Particularity and Responsiveness," in The Emergence of Morality in Young Children, ed. Kagan, J. and Lamb, S., (Chicago and London: Chicago University Press), pp. 306-337.

Burghardt, Gordon M., (1992) "Human-bear bonding," in The Inevitable Bond, ed. Davis, H. and Balfour, A.D., (New York: Cambridge University Press), pp. 365-382.

Carruthers, Peter, (1992) The Animals Issue, (Cambridge: Cambridge University Press).

Crowell-Davis, Sharon L., (1992) "Effect of the researcher on the behavior of horses," in The Inevitable Bond, ed. Davis, H. and Balfour, A.D., (New York: Cambridge University Press), pp. 316-333)

Davis, H. (1989), "Theoretical Note on the Mora1 Development of Rats (Rattus-norvegicus)," Journal of Comparative Psychology 103, 88-90. 
Evans, George Ewart (1979), Horse Power and Magic, (London: Faber and Faber).

George, Kathryn Paxton, (1992) 'Moral and Nonmoral Innate Constraints," Biology and Philosophy, 7: 189-202.

Harris, Paul L., (1991) "The Work of the Imagination," in Natural Theories of Mind, (Oxford: Basil Blackwell), pp. 283-304.

Hearne, Vicki, (1987) Adam's Task (London: William Heinemann Ltd).

Hemsworth, P., Barnett, J., Coleman, G., (1992) "Fear of humans in the domestic pig," in The Inevitable Bond, ed. Davis, H. and Balfour, A.D., (New York: Cambridge University Press), pp. 264-284.

Howlin, Patricia and Rutter, Michael (1987) Treatment of Autistic Children, (Chichester: John Wiley).

Humphrey, N.K. (1986), The Inner Eye, (London: Faber and Faber)

Murdoch, Iris, ( 1970), The Sovereignty of Good (London: Routledge \& Kegan Paul).

Murdock, G.P., (1980), Theories of Illness (Pittsburgh: University of Pittsburgh Press).

Povinelli, DJ, Deblois, S., (1992) "Young Children's (HomoSapiens) Understanding of Knowledge Formation in Themselves and Others," Journal of Comparative Psychology, 106, 228-238.

Ross, Angus (1983) "The Status of Altruism," Mind, 42, 204-18.

Shweder, Richard A., and Much, Nancy C., (1987) "Determinations of Meaning: Discourse and Moral Socialization" in Moral Development through Social Interaction, ed. William M. Kurtines and Jacob L. Gewirtz, (New York: Wiley-Interscience), pp. 197-244.

Wellman, Henry M., (1990) The Child's Theory of Mind, (Cambridge, Massachusetts: MIT Press)

Whiten, Andrew (ed.), (1991) Natural Theories of Mind, (Oxford: Basil Blackwell)

Williams, Moyra, (1971) A Breed of Horses, (Oxford: Pergamon Press)

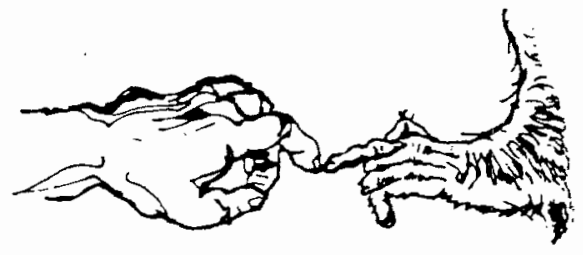

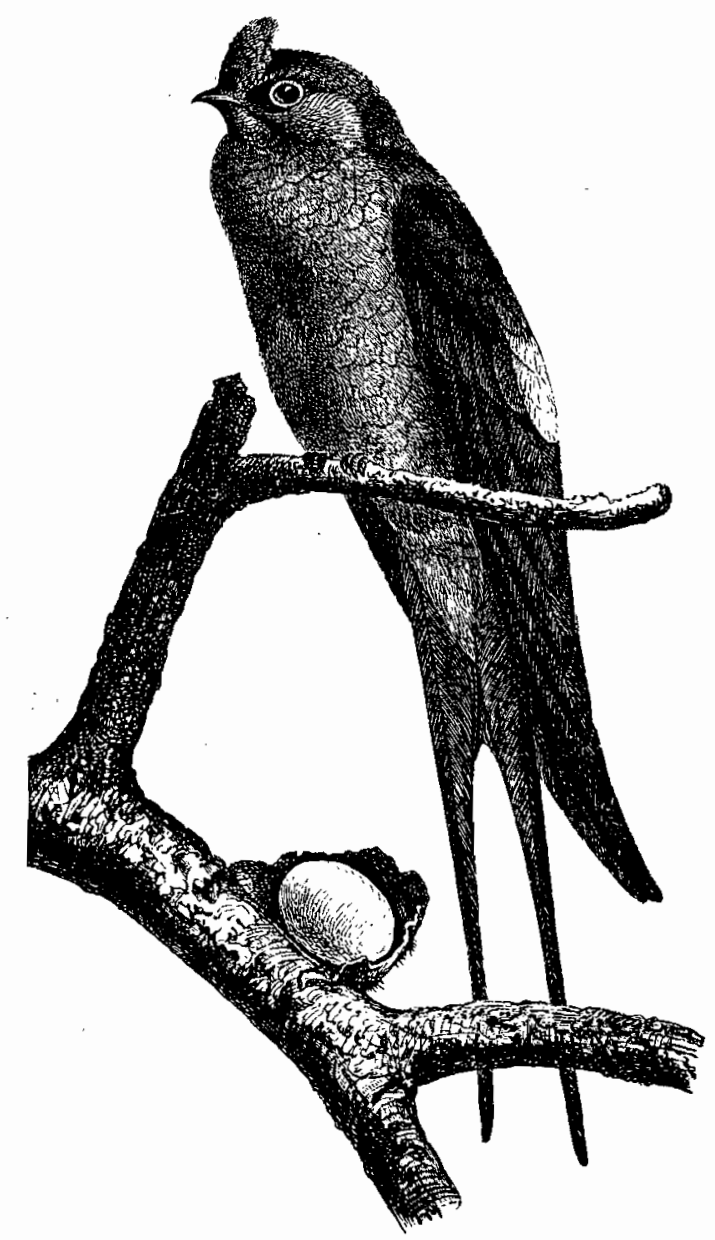

Between the Species 